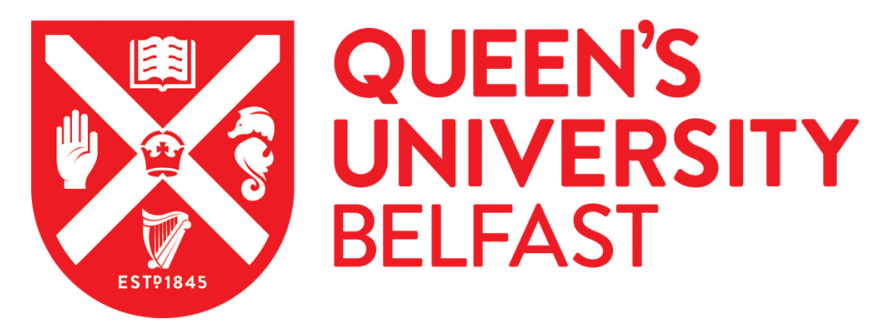

\title{
Analysis of Load Test on Composite I-Girder Bridge
}

Huseynov, F., Brownjohn, J. M. W., O'Brien, E. J., \& Hester, D. (2017). Analysis of Load Test on Composite IGirder Bridge. Journal of Civil Structural Health Monitoring, 7(2), 163-173. https://doi.org/10.1007/s13349-0170223-x

Published in:

Journal of Civil Structural Health Monitoring

Document Version:

Peer reviewed version

Queen's University Belfast - Research Portal:

Link to publication record in Queen's University Belfast Research Portal

Publisher rights

(C) 2017 Springer-Verlag Berlin Heidelberg.

This work is made available online in accordance with the publisher's policies. Please refer to any applicable terms of use of the publisher.

\section{General rights}

Copyright for the publications made accessible via the Queen's University Belfast Research Portal is retained by the author(s) and / or other copyright owners and it is a condition of accessing these publications that users recognise and abide by the legal requirements associated with these rights.

Take down policy

The Research Portal is Queen's institutional repository that provides access to Queen's research output. Every effort has been made to ensure that content in the Research Portal does not infringe any person's rights, or applicable UK laws. If you discover content in the Research Portal that you believe breaches copyright or violates any law, please contact openaccess@qub.ac.uk. 


\title{
1 Analysis of Load Test on Composite I-Girder Bridge
}

\author{
2 F.Huseynov ${ }^{1,2}$, J.M.W. Brownjohn ${ }^{3}$, E.J. O’Brien², D. Hester ${ }^{4}$ \\ 3 \\ $4 \quad{ }^{1}$ Full Scale Dynamics LTD, Kay Building North Park Road, Exeter EX4 4QF \\ $5 \quad{ }^{2}$ School of Civil Engineering, University College Dublin, Richview Newstead \\ 6 Block B, Belfield, Dublin, Ireland \\ $7 \quad{ }^{3}$ Vibration Engineering Section, College of Engineering, Mathematics and \\ 8 Physical Sciences, University of Exeter, North Park Road, EX4 4QF Exeter, \\ 9 UK \\ $10{ }^{4}$ School of Natural and Built Environment, Queen's University Belfast, \\ 11 Stranmillis Road, BT9 5AG Belfast, Northern Ireland, UK
}

Contact author:

Farhad Huseynov

Kay Building North Park Road,

Exeter. UK

EX4 6BH

E-mail: f.huseynov@fullscaledynamics.com

Tel: +447533118686

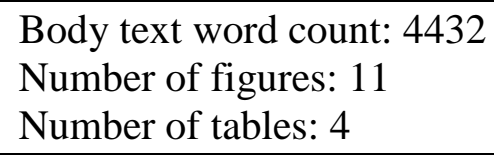


1 Abstract

2 This paper showcases the importance of field testing in efforts to deal with the

3 deteriorating infrastructure. It shows that when tested, bridges do not necessarily

4 behave as expected under load, particularly with respect to boundary conditions. This

5 is demonstrated via a load test performed on a healthy but aging composite reinforced

6 concrete bridge in Exeter, UK. The bridge girders were instrumented with strain

7 transducers and static strains were recorded while a four-axle, 32 tonne lorry remained

8 stationary in a single lane. Subsequently, a 3-D finite element model of the bridge was

9 developed and calibrated based on the field test data. The bridge deck was originally

10 designed as simply supported, however, it is shown (from the field test \& calibrated

11 model) that the support conditions were no longer behaving as pin-roller which affects

12 the load distribution characteristics of the superstructure. Transverse load distribution

13 factors (DFs) of the bridge deck structure were studied for different boundary

14 conditions. The DFs obtained from analysis were compared with DFs provided in

15 Design Manual for Roads and Bridges (DMRB) Standard Specification. Having

16 observed in the load test that the ends of the deck appeared to be experiencing some

17 rotational restraint, a parametric study was carried out to calculate mid-span bending

18 moment (under DMRB assessment loading) for varying levels of restraint at the end of

19 the deck.

20 Keywords:

21 Bridge Field Testing, Strain Measurements, Load Distribution Factors, FE Modelling, 22 Bridge Assessment 


\section{$1 \quad 1$ Introduction}

2 Bridges are expensive and critical structures that connect communities and serve as

3 regional lifelines. Over time, they are exposed to many degradation processes due to

4 environmental factors and changing loading conditions. It is found in recent studies

5 that more than half of the Europe's 1 million bridges were built before 1965 and so

6 they are nearing the end of their 50-year design lives [1]. Their replacement cost is

7 equal to $30 \%$ of gross domestic product so it is not feasible to replace them. Thus,

8 bridge owners are particularly interested in accurate and inexpensive methods for

9 verifying remaining service life and safety of such aging structures.

10 Current bridge evaluation techniques are mainly based on qualitative assessment and

11 can fail to estimate the hidden strength reserve of aging bridge assets in many cases.

12 Based on such methods, more than $20 \%$ of 155,000 bridges in the UK are reported as

13 structurally deficient in some form [2]. However, the actual load-carrying capacity of

14 structures is often higher than predicted by analysis [3]. For example, a load test was

15 performed on a decommissioned skewed I-girder steel bridge where test load of 17

16 times higher than the anticipated load was applied to the bridge and results showed

17 that it had been decommissioned despite a significant remaining load capacity [4]. In

18 another study, a 50-year-old Swedish reinforced concrete railway bridge was tested to

19 failure [5]. The results indicated that the bridge could sustain almost five times the

20 design load. Those reserve capacities come from additional sources of strength not

21 normally taken into account in the conventional assessment methods and are

22 associated with several factors such as higher girder/deck composite action, superior

23 material strength, girder end restraints, dynamic impact, unexpected transverse load

24 distribution due to material inelasticity, contribution of non-structural elements such

25 as kerbs, parapets etc.. Thus, field testing is an important topic in an effort to deal with 
1 the deteriorating infrastructure, since it can reveal hidden reserves of structural

2 strength at the same time verifying safety.

3 Current bridge evaluation specification in the UK, Design Manual for Roads and

4 Bridges (DMRB), is built on already available design standards, which contain

5 degrees of uncertainty that understandably lead to conservative results. Although they

6 fit the purpose for the design of new structures, for the assessment of aging bridge

7 assets such uncertainties add up and can obscure the remaining strength reserve of

8 structures. One of the main sources of such uncertainties involved in DMRB Standard

9 Specification is associated with the methods used for calculating the load effects for

10 assessment purposes. For example, transverse load distribution factors (DFs)

11 recommended by the code are typically quite high. Obviously the values given in the

12 code have to cover a wide range of bridge types and loading conditions and as a result

13 are understandably conservative. However, the reality is that every bridge presents a

14 unique situation which has its own characteristics and requirements.

15 To demonstrate the kind of 'individual behaviour' that a bridge can have, i.e. different

16 to the idealised behaviour expressed in the DMRB Standard Specification, this study

17 presents the results of a load test performed on a composite reinforced concrete bridge

18 in Exeter, UK where strain transducers were installed on bridge girder soffits and

19 quasi-static strain response were recorded under 32 tonne, four axle truck loading. In

20 parallel, a 3 - D FE model of the structure was developed and calibrated based on the

21 load test data to study the behaviour of the structure under static loading. The bridge

22 support conditions were originally designed to move freely in the longitudinal

23 direction however, it was observed during the FE model calibration that the bridge

24 boundary conditions no longer behave this way and the structure experiences a certain

25 level of restraint at support locations. Load-shedding characteristics of the 
1 superstructure were also studied within the scope of this work where DFs of the deck

2 structure were calculated for different boundary conditions and compared with the DF

3 value provided in DMRB Standard Specification for a similar bridge type. Having

4 observed the change in the boundary conditions, a parametric study was conducted to

5 study the effect of translational restraint on load effects under DMRB assessment

6 loading. Load effects were calculated for varying levels of translational restraints at

7 the end of the deck and it was demonstrated through parametric studies that an

8 accurate representation of boundary conditions could reveal strength reserves in a

9 bridge during a bridge assessment. 


\section{$1 \quad 2$ Test Structure}

2 Two almost identical adjacent bridges known as Exe North and South Bridges form a

3 large roundabout spanning the River Exe in Exeter, UK. Exe North Bridge was chosen

4 as a test structure. It is $59.35 \mathrm{~m}$ long and consists of two $19.85 \mathrm{~m}$ outer spans and a

$5 \quad 19.61 \mathrm{~m}$ centre span, resting on two wall-type pier structures in the river and abutments

6 at the ends. It was constructed in 1969 to replace the previous three-hinged steel arch

7 bridge.

8 The superstructure is $18.9 \mathrm{~m}$ wide, carrying four lanes of traffic and connecting

9 Okehampton Street (South) with Bonhay Road (North). The first lane is $4 \mathrm{~m}$ wide and

10 designated as a bus lane. The other three lanes are $3-3.25 \mathrm{~m}$ wide and used by public

11 traffic. The superstructure is $1 \mathrm{~m}$ deep and consists of 12 composite precast girders

12 placed at $1.53 \mathrm{~m}$ apart and a $0.23 \mathrm{~m}$ deep cast in situ reinforced concrete deck. The

13 girder elements were designed as composite type, where steel beams were embedded

14 in reinforced concrete I-girders. The steel beams are 762x267x197 mm universal

15 beams with additional plates welded to the top and bottom flanges. Full composite

16 action between steel and concrete girders is provided through double shear connectors,

17 closely placed $(125 \mathrm{~mm})$ at supports and gradually increasing towards the mid-span

18 (500mm).

19 Based on the available drawings the substructure consists of two wall-type pier

20 structures and two cantilever type abutments at 15 degrees skew with respect to spans

21 and parallel to the river bank. The connection between superstructure and substructure

22 is provided with laminated elastomeric bearings (see inset in Figure 2(a)). These

23 consist of alternating layers of rubber and steel plates and are designed to produce a

24 vertically stiff but longitudinally flexible support condition for the bridge structure and

25 are commonly installed to provide pin-roller type support conditions. Continuity 
1 between spans is cut off by $10-25 \mathrm{~mm}$ wide gaps filled with bituminous rubber so

2 that each span is simply supported.

3 Fig. 1 (a), (b) and (c) respectively show the bridge elevation, plan and cross section.

4 Fig. 2 shows a picture of the bridge, and the structural characteristics of the bridge

5 summarized in Table 1 . Since the spans are not continuous, only the north span was 6 chosen for testing purposes (this is the right hand span in Fig. 2). 


\section{$1 \quad 3$ Instrumentation and Testing}

2 ST350 model strain transducers provided by Bridge Diagnostics, Inc. (BDI) were used

3 to measure the strains during the field test. These are reusable Wheatstone full bridge

4 resistive sensors encased in rugged transducer packages that are mounted on the

5 structure with bolted tabs. The strain sensor itself is $76 \mathrm{~mm}$ long, but the gauge length

6 of sensors is $0.6 \mathrm{~m}$ as aluminium extension rods are used to account for local

7 microcracks that can occur in RC structures and average strain values are recorded.

8 Fig. 3 shows the sensor installed on a girder soffit. These sensors are wired into three

9 4-channel nodes wirelessly linked to a host data acquisition system. The data are

10 recorded with a sampling rate of $250 \mathrm{~Hz}$. Based on the gain, excitation and full-scale

11 range of the sensors and software settings, 0.3 microstrain resolution is determined for

12 the measurement readings.

13 The bridge spans over water, which made installation a difficult task. The only access

14 to the deck soffit, (avoiding working in water), was at the quarter span, through the 5

15 m wide footpath along the river bank. Hence, the strain transducers were installed on

16 each girder soffit at quarter span close to the North abutment. Ideally, it would have

17 been better also to be able to record strains at midspan during the test as this would

18 provide additional data to check the numerical model against, but unfortunately in this

19 case this was not logistically faesible. However, it is felt that having multiple

20 measurements from the quarter span (i.e. gauges installed at each girder) is sufficent to

21 calibrate reliably the FE model. Gauges installed on each girder also allow the load -

22 shedding characteristics of the superstructure to be studied. The plan view of the

23 sensor layout is provided in Fig. 4. The beams are indicated as red lines and the

24 sensors are labelled 1-12.

25 The test vehicle used was a four-axle 32 tonne lorry, and this was used to obtain quasi- 
1 static strain response. Fig. 5 (a) shows the truck during the load test. It has axle

2 spacing of $1.94 \mathrm{~m}, 3.56 \mathrm{~m}$ and $1.35 \mathrm{~m}$ from front to rear. Fig. 5 (b) depicts the axle

3 configurations and Table 2 tabulates weight for each axle. The truck made several

4 passes in each of the four lanes (Lane 1, Lane 2, Lane 3, and Lane 4), stopping every

5 time for 30-45 seconds to record the quasi-static strain. The front axle of the truck,

6 while it was stationary, aligned approximately with the supports at the north abutment,

7 with vehicle centre of gravity in line with sensor locations. Fig. 4 illustrates the

8 positioning of the vehicle in each of the four lanes. 16 passes were made in total (4

9 passes per lane) and the test was performed overnight to avoid traffic on the bridge. In

10 the load cases corresponding to Lane 1 and Lane 4, the exterior most wheel line is

11 approximately $0.8 \mathrm{~m}$ and $0.3 \mathrm{~m}$ from the kerb, respectively.

12 Fig. 6 illustrates a typical strain-time history recorded during the test. Fig. 7 shows the 13 average strain calculated in each girder for truck positions in Lane 1-4. The 14 implications of the test are described in detail in the following sections. 


\section{Numerical Model of the Bridge}

2 Since it was not possible to install the sensors at midspan of the deck structure, a 3-D

3 FE model of the bridge was developed to study the load effects at midspan location

4 under similar loading conditions applied during the field testing. The FE model was

5 developed according to available structural design drawings using ANSYS V16.0

6 software [6]. The model includes all the necessary geometric details with composite

7 structural configurations. The model was developed using SOLID185 elements to

8 obtain reliable strains and accurate representation of steel concrete composite

9 behaviour. Since the spans are non-continuous and independent, only the tested

10 (North) span was considered during the modelling. Fig. 8 (a) illustrates the FE model

11 of steel stringers and Fig. 8 (b) shows full/final 3-D FE model of the Exe North

12 Bridge.

13 The bridge model represents concrete I-girders, steel stringers with stiffening plates at

14 top and bottom flanges. Each part of the model was developed separately in ANSYS

15 native scripting language, with parts merged using the NUMMRG command to form

16 the complete model of the Exe North Bridge structure. Subsequently, mesh

17 verification analysis was carried out using a convergence study on mesh size for

18 midspan deflection under an arbitrary load, leading to a final choice of $250 \mathrm{~mm}$ mesh

19 size Designed mesh size was also sufficiently fine to be able to simulate different

20 truck loading conditions over the bridge.

21 Pier and abutment structures were excluded from the FE model as they are assumed to

22 be infinitely rigid in axial directions. At each support location, the elastomeric

23 bearings were represented in the numerical model by releasing the longitudinal

24 displacements. During the model calibration, different boundary conditions were

25 considered and these are described in detail in the following section. Many previous 
1 studies investigated the effect of skew angle on load distribution characteristics of

2 bridge deck structures and it has been reported that skew has little effect $(<1 \%)$ for an

3 angle smaller than 20 degrees for this type of bridge [7, 8]. Therefore, the bridge was

4 modelled without a skew angle.

5 


\section{Results and Discussions}

2 Similar load cases applied during the load test were simulated on the 3-D FE model

3 and different boundary conditions were studied to understand the behaviour of the

4 structure under static loading. Strain values predicted for each boundary condition

5 using numerical model were compared with data obtained from the field test. It was

6 observed that the bridge boundary conditions have likely changed compared to the

7 likely original design assumption, i.e. being simply supported (section 5.1). Later, the

8 calibrated model was used to study the likely load-shedding characteristics of the

9 bridge which were compared to those prescribed by the DMRB Standard Specification

10 (section 5.2). Finally, a parametric study was carried out to examine how the load

11 effects under assessment loading specified by DMRB Standard Specification are

12 affected by changes to the boundary conditions (section 5.3).

\section{$13 \quad 5.1$ Comparing FE strain predictions to field data}

14 Once the average strain values for each girder were obtained based on the field test

15 (Fig. 7), similar loading cases were simulated using the FE model. Fine meshing made

16 it possible to locate accurately the truck axle configuration at each lane. Several

17 scenarios were studied to understand the current structural condition of the bridge and

18 its behaviour under applied load which are discussed in detail below.

19 Ultimately, three different boundary conditions were studied to investigate the

20 behaviour of the bridge deck. However, initially, only two were simulated. In the first

21 case, the bridge support conditions were assigned as a hinge at one end and roller at

22 the other end (hinge-roller case), which is similar to the likely initial design

23 assumption. In the second case, longitudinal movement of supports at both ends was

24 restrained (hinge-hinge case). Fig. 9 (a)-(d) show the measured and theoretical girder 
1 strains (for different boundary conditions) for the truck positioned in lanes 1-4

2 respectively. Results show that measured (test) strains (black plot, diamond data

3 markers) lay between two limits of boundary conditions, hinge-hinge (red plot, star

4 data markers) and hinge-roller (green plot, circular data markers), which implies that

5 bridge boundary conditions are partially restrained. The third boundary condition tried

6 to simulate this partial restraint by taking the hinge - roller model and adding

7 longitudinal springs to the top and bottom flanges at the ends of the girder. Fig. 10

8 shows the schematic drawings of the three cases of boundary conditions used for finite

9 element analysis. Longitudinal springs at top and bottom flange of the girder for the

10 partially restrained boundary condition is equivalent to a rotational restraint. The

11 springs were modelled with springs using ANSYS COMBIN14 elements attached to

12 top and bottom flanges of girders. Springs at the bottom flanges represent the

13 longitudinal stiffness of the elastomeric bearings whereas at top flanges they represent

14 the longitudinal restraint provided by the expansion joint. Estimating the degree of

15 partial stiffness of the elastomeric bearings was a challenging task. To have an idea

16 about the maximum possible level of restraint, initially, an equivalent spring

17 coefficient that would reproduce the hinge - hinge boundary condition was estimated

18 as $\sim 24 \mathrm{MN} / \mathrm{mm}$ by trial and error method (i.e. springs in the bottom right of Fig.10c

19 has stiffness of $24 \mathrm{MN} / \mathrm{mm}$ and the two springs on the top fibre of figure 10c have a

20 stiffness equal to zero). Admittedly elastomeric bearings are not designed to have such

21 a degree of longitudinal stiffness however, it provided a reference value for obtaining

22 the degree of longitudinal stiffness for partially restrained boundary condition. In

23 reality, the degree of partial fixity also can vary from girder to girder and it is difficult

24 to identify such differences accurately and apply the corresponding spring

25 coefficients. In this study, girders were grouped, and suitable spring coefficients $\left(\mathrm{K}_{\mathrm{spr}}\right)$

26 for partially restrained boundary condition were chosen by trial and error. The degree 
1 of longitudinal stiffness of elastomeric bearings varied between $1.2-2.4 \mathrm{MN} / \mathrm{mm}$. It

2 was concluded that movement of elastomeric bearings in the longitudinal direction is

3 partially fixed. It was also observed that bearings under girders 3-8 are more restrained

4 than the others. The specific reason for the greater restraint in these beams is not

5 properly understood. Traffic flow at the site is such that this lane experiences the

6 greatest proportion of trucks so the bearings under this lane are likely to have

7 experienced a larger load over time. However it is not known if this is a factor in the

8 currently larger apparent restraint of these bearings.. Results obtained from the FE

9 model with partially restrained boundary conditions are shown in Fig 11 (blue plot,

10 triangular data markers) are in good agreement with the field test data for all 4 lanes.

11 The foregoing study clearly shows that changes in bearing conditions, i.e. a degree of

12 rotational restraint at the supports significantly reduce load effect (tensile stress in

13 bottom fibre) in the bridge girder This restraint at the end of the deck could impact on

14 the load carrying capacity of the bridge in a positive way, i.e. reducing the stress in the

15 extreme fibre at mid-span. Admittedly this reduction in the expected stress in the

16 bottom fibre at mid-span may have negative outcomes in other parts of the deck, i.e.

17 increases in stress, so that needs to be taken into consideration. However, the above

18 results demonstrate that field testing is an important tool when evaluating aging bridge

19 assets as it could reveal hidden strength reserves which current bridge inspection

20 techniques fail to identify.

\section{$21 \quad 5.2$ Distribution factors}

22 Transverse load distribution factors (DFs) are a measure of the transverse load transfer

23 through the structure. Bridges are typically designed in such a way that traffic load is

24 distributed between girders as "fairly" as possible so as not to overstress any particular

25 load carrying member. Therefore, in load carrying assessment of a beam and slab 
1 bridge, the DFs specified by the code play a very important part in the calculation. For

2 example, when a load is in a particular lane, a high DF implies there is little load

3 sharing between adjacent girders and therefore the portion of the load carried by the

4 girder(s) under the load is assumed to be quite high and assessment will be

5 conservative. Therefore, obtaining DFs is of vital importance for any bridge

6 assessment activity.

7 Any change in bridge condition during its service life might significantly affect its

8 load distribution characteristics. Having seen in the previous section how the

9 magnitude of strain is affected by changes in the boundary conditions, in this section

10 the impact of the boundary conditions on the DFs is examined. Having seen good

11 agreement between analytical and measured strain data at quarter span (assuming

12 partial restraint) the numerical model is used to predict the DFs at midspan. These are

13 then compared to the DFs specified in DMRB Standard Specification. DFs considered

14 in this study are related to bending moment and DFs for shear are not included within

15 the scope of this study. Stress based DFs were computed using the following equation.

$$
D F_{i}=\frac{\sigma_{i}}{\sum \sigma_{i}}=\frac{E_{i} \varepsilon_{i}}{\sum E_{i} \varepsilon_{i}}=\frac{\varepsilon_{i}}{\sum \varepsilon_{i}}
$$

17 Where:

$18 \sigma_{\mathrm{i}} \quad=$ stress at soffit of girder i

$19 \mathrm{E}_{\mathrm{i}} \quad=$ Modulus of Elasticity of concrete

$20 \quad \varepsilon_{\mathrm{i}} \quad=$ Strain measured at soffit girder $\mathrm{i}$

21 Modulus of elasticity values is assumed to be constant for all girders.

22 Since it was not possible to install strain sensors at midspan, further analyses were

23 carried out with the bridge FE model loaded with an equivalent truck load at all lanes

24 at midspan to obtain the relevant DF of the deck structure. Truck axle positions were 
1 located so that centre of gravity was in line with midspan location and results obtained

2 from the FE model were compared with DFs provided in the Design Manual for Roads

3 and Bridges (DMRB) Standard Specification [9]. DFs for bridge construction with a

4 concrete deck on precast I-girders are derived from relevant graphs provided in

5 DMRB Standard Specification as 0.495 and 0.472 for internal and external girders,

6 respectively. The DFs calculated from the DMRB Standard Specification depend on

7 the spacing of the girders, span length, skew angle and the number of lanes on the

8 bridge. Fig. 10 illustrates simulated strains obtained for different boundary conditions

9 and corresponding DFs calculated from numerical models. These are compared with

10 calculations using DMRB Standard Specification for 32 tonne truck loaded in each

11 lane. Fig. 11 (a) shows the midspan strain in each of the 12 girders when there are 4

12 trucks "parked" at midspan, i.e. one truck in each of lanes 1-4. As with quarter span

13 the magnitude of the strain experienced is sensitive to the boundary conditions

14 simulated. Fig 11 (b) shows the corresponding transverse load distribution factors

15 (DFs) for each of the 12 girders (calculated using Eq.1) for three different boundary

16 conditions (hinge-hinge, hinge-roller, and partially fixed). It can be seen in the figure

17 that the hinge-hinge and partially fixed boundary conditions lead to higher DFs than

18 the hinge - roller boundary condition, i.e. greater restraint at the end of the beam leads

19 to less load sharing between adjacent members. The horizontal dashed line in the plot

20 shows the DFs specified by DMRB Standard Specification for an internal girder (for

21 simply supported boundary condition). This value is slightly conservative with respect

22 to the hinge roller boundary condition (which is likely the intention of the code).

23 However, it is actually not conservative if the boundary conditions had changed to

24 hinge - hinge, or partially fixed. The numerical model with partial fixity still includes

25 some errors. Such errors, while low, will affect the calculated DF. In Fig. 11(b), any

26 remaining model errors may have caused the DMRB specified DF to appear non- 
1 conservative. However, the degree of un-conservativeness is very small, and would

2 likely be offset by the reduction in stress observed in the bottom fibre (due to the

3 restraint).

\section{$4 \quad 5.3$ Parametric study of boundary conditions vs. midspan moment}

5 The main observation from sections 5.1 and 5.2 is that the structural behaviour of the

6 bridge can be significantly different from that envisaged by the assessment code. To

7 examine this further, in this section a parametric study is carried out to examine how

8 the midspan moment under assessment loading is affected by changes in the boundary

9 conditions. The load to be applied to the beam is determined from the Design Manual

10 for Road and Bridges (DMRB) Standard Specification, then in one simulation the

11 beam is treated as simply supported, in another it is assumed to have the rotational

12 restraints (i.e. longitudinal springs on the top and bottom flanges) observed during the

13 field test, and finally the moment is calculated for a series of intermediate levels of

14 rotation restraint. The analysis presented in this section to calculate a load effect of a

15 girder for different boundary conditions is performed using a simple (1 - D) finite

16 element beam model. Section 5.3 .1 gives an overview of the DMRB Standard

17 Specification and section 5.3.2 reports the results of the parametric study. 


\section{$1 \quad$ 5.3.1 Overview of loads to be applied during a bridge assessment}

2 Bridges in the UK are assessed to carry the load effects of the Type HA design

3 loading that covers the load effects of vehicles up to 40/44 tonnes. For short to

4 medium span bridges the type HA loading is represented by uniformly distributed load

5 (UDL), derived from equation (2), and applied in conjunction with a knife edge load

6 (KEL) of $120 \mathrm{kN}$ [9].

$$
W=336\left(\frac{1}{L}\right)^{0.67}
$$

8 Where:

$9 \mathrm{~W}=$ is the uniformly distributed load in $\mathrm{KN}$ per metre length of a lane

$10 \mathrm{~L} \quad=$ is span length in metres.

11 The type HA UDL and KEL loadings specified in DMRB Standard Specification are

12 determined using probabilistic approaches based on the four elements which are a)

13 loading from all the possible vehicles controlled by The Road Vehicle (Authorised

14 Weight (AW)) Regulations 1998 as amended, b) Impact, c) Overloading and d)

15 Lateral bunching.

16 Loading from AW vehicles is applied to the type HA load model by assuming that all

17 lanes on a bridge structure are fully loaded with particular vehicles. Impact associated

18 with dynamic effects of traffic loading is included only for a single vehicle and a

19 factor of 1.8 is applied to the heaviest axle based on the report published by TRRL

20 [10]. The effect of overloading is estimated based on the surveys carried out by TRRL

21 where static weights of vehicles were monitored at three main road sites and applied in

22 terms of extreme overloading factor which is derived dependent on a span length [11,

23 12]. Lateral bunching, which is a possibility of having two lines of convoys in a lane, 
1 is applied as a factor based on the ratio of standard lane width, $3.65 \mathrm{~m}$, to the

2 maximum width of a vehicle, $2.5 \mathrm{~m}$. Each of these elements described above includes

3 a certain level of conservatism in some form.

4 Recent data indicates that type HA loading used for design purposes can be relaxed for

5 assessment activities to get less onerous effects, while maintaining the consistent

6 reliability level for the whole network [13]. Besides, probabilistic studies show that

7 impact factor due to dynamic effect of traffic loading, which occurs at high speeds,

8 should not be considered together with lateral bunching. Therefore, DMRB advices a

9 reduction factors such as Adjustment Factor (AF) and Reduction factor (K) to be

10 applied both for UDL and KEL. Hence, Bridge Specific Loading specified by DMRB

11 Standard Specification was calculated by multiplying both UDL and KEL with

12 Reduction factor and dividing by Adjustment Factor. The Type HA loading was also

13 factored with partial factor $\left(\gamma_{\mathrm{fL}}\right)$ to give the 40/44 tonnes Assessment Live Loading

14 and Assessment Load Effect factor $\left(\gamma_{\mathrm{f}}\right)$ to account for any inaccuracies involved in a

15 bridge assessment activity, i.e. inaccuracies involved in calculation models.

$16 \quad \underline{5.3 .2 \text { Calculating load effects and results of parametric study }}$

17 Having applied the loads specified in section 5.3.1 to the deck, Assessment Load for a

18 single girder (critical) was obtained by multiplying the load of a single lane by the

19 transverse load distribution factors (DFs) provided in DMRB Standard Specification.

20 Once the load to be applied to an individual girder was known the load effect

21 (midspan bending moment) was calculated using a simple finite element beam model.

22 If simple supports are assumed, there is no need for a finite element model. However,

23 the objective of this section is to examine how midspan moment is affected by varying

24 the level of rotational restraint at the support so a 1-D numerical model is required for 
this.

2 Work by [14] shows that the longitudinal stiffness of an elastomeric bearing decreases

3 with increasing load. Essentially the end restraint if the deck is loaded with HA

4 loading is likely to be significantly less than the level of end restraint observed when

5 the deck is loaded with a single 32 tonne truck. Therefore, three different spring

6 coefficients were simulated being $100 \%, 60 \%$ and $30 \%$ of the spring stiffness obtained

7 from the field testing (with a 32 tonne truck). Table 3 identifies the different loads and

8 factors that were common to all simulations. Table 4 presents the assessment

9 parameters that changed slightly with variation in end restraint, and the bold text in the

10 table shows the bending moment for each case. The italic text in the last row shows

11 the ratio between the midspan moment predicted by the FE model with partial restraint

12 and the simply supported model. In the table, it can be seen that if the end restraint is

13 simulated as being $30 \%$ of the full restraint when there was a 32 tonne truck on the

14 bridge this still results in a midspan moment which is $18 \%$ less than if the girder is

15 assumed to be simply supported. Admittedly the level of end restraint under Ultimate

16 Limit State (ULS) (DMRB) loading is unknown and in the absence of any other

17 information assuming zero restraint (i.e. assume simply supported) is conservative and

18 appropriate. However, the results in Table 4 show that in a situation where a bridge

19 marginally fails an initial load carrying assessment, some field testing might uncover

20 behaviour (at loads lower than HA loading) that would allow the assessor to revise his

21 structural model (at ULS loading) sufficiently such that bridge would pass the 22 assessment. 


\section{Summary and Conclusions}

2 A load test was conducted on the North Span of the Exe North Bridge in Exeter, UK

3 where 12 strain transducers were attached to the soffit of the girders at quarter span to

4 record static strains due to a four-axle, 32 tonne truck. Subsequently, 3-D FE model of

5 the bridge was developed and calibrated based on the field test data. The following

6 conclusions result from this study:

- Change in boundary conditions (i.e. degree of translational restraint at the supports) can significantly reduce bending moment effects at midspan in bridge girders.

- Greater restraint at the end of a deck leads to reduced load sharing between girders and as a result, increases transverse load distribution factors (DFs) and hence reduces load carrying capacity of a structure.

- Field testing is an important topic in an effort to dealing with evaluation of aging bridge assets, with a capability to reveal hidden strength reserves.

\section{$15 \quad 7$ Acknowledgements}

16 This research project has received funding from the European Union’s Horizon 2020

17 research and innovation programme under the Marie Skłodowska - Curie grant

18 agreement No. 642453. The authors would like to acknowledge the Devon County

19 Council, in particular, Mark Colville for facilitating the field test. Additionally, the

20 authors also wish to thank undergraduate student Nick Trump for his assistance during

21 the field test and data analysis. 


\section{Tables}

2 Table 1 Summary of the bridge structural characteristics

\begin{tabular}{|l|l|}
\hline Total bridge length & $59.35 \mathrm{~m}$ \\
\hline Number of spans & 3 \\
\hline Span lengths & $19.85 \mathrm{~m}, 19.61 \mathrm{~m}, 19.85 \mathrm{~m}$ \\
\hline Continuity & Simple supported \\
\hline Skew angle & 15 degrees \\
\hline Deck type & composite I-girders in situ RC deck \\
\hline Deck width & $18.9 \mathrm{~m}$ \\
\hline Number of lanes & 4 \\
\hline Deck depth & $1 \mathrm{~m}$ \\
\hline Substructure type & Cantilever type abutment and wall-type pier \\
\hline Bearing type & Laminated elastomeric bearing \\
\hline
\end{tabular}

3 Table 2 Axle weight configuration of the test vehicle

\begin{tabular}{|c|c|}
\hline Truck Axles & $\begin{array}{c}\text { Axle Weight } \\
(\mathrm{kN})\end{array}$ \\
\hline Axle -1 (Front) & 67.2 \\
\hline Axle -2 & 67.2 \\
\hline Axle -3 & 89.8 \\
\hline Axle -4 (Rear) & 89.8 \\
\hline
\end{tabular}

4 
1 Table 3 Common parameters used in assessment

\begin{tabular}{|c|c|c|c|c|c|}
\hline $\begin{array}{c}\text { Uniformly } \\
\text { Distributed } \\
\text { Load }(\mathrm{kN} / \mathrm{m})\end{array}$ & $\begin{array}{c}\text { Knife Edge } \\
\text { Load }(\mathrm{kN})\end{array}$ & $\begin{array}{c}\text { Adjustment } \\
\text { Factor }\end{array}$ & $\begin{array}{c}\text { Reduction } \\
\text { Factor }\end{array}$ & $\begin{array}{c}\text { Partial } \\
\text { Factor } \\
\left(\gamma_{\mathrm{fL}}\right)\end{array}$ & $\begin{array}{c}\text { Assessment } \\
\text { Load Effect } \\
\text { factor }\left(\gamma_{\mathrm{f} 3}\right)\end{array}$ \\
\hline 46 & 120 & 1.46 & 0.78 & 1.5 & 1.1 \\
\hline
\end{tabular}

3 Table 4 Summary of the results for Assessment Live Load calculations

\begin{tabular}{|c|c|c|c|c|}
\hline \multirow{2}{*}{$\begin{array}{l}\text { Type HA Load and } \\
\text { associated factors }\end{array}$} & \multirow{2}{*}{$\begin{array}{l}\text { Simply } \\
\text { Supported } \\
\text { Model } \\
\text { (DMRB) }\end{array}$} & \multicolumn{3}{|c|}{$\begin{array}{l}\text { Partially restrained Model } \\
\text { (DFs obtained from the field testing) }\end{array}$} \\
\hline & & $30 \% \mathbf{K}_{\mathrm{spr}}$ & $60 \% K_{\text {spr }}$ & $100 \% K_{\text {spr }}$ \\
\hline $\begin{array}{l}\text { Transverse Load } \\
\text { Distribution Factor (DF) }\end{array}$ & 0.495 & 0.512 & 0.512 & 0.512 \\
\hline $\begin{array}{l}\text { Assessment Live Load - } \\
\text { UDL }\end{array}$ & 20.1 & 20.8 & 20.8 & 20.8 \\
\hline $\begin{array}{l}\text { Assessment Live Load - } \\
\text { KEL }\end{array}$ & 52.4 & 54.2 & 54.2 & 54.2 \\
\hline $\begin{array}{l}\text { Assesment Live Load } \\
\text { effect (Moment) on } \\
\text { critical girder }\end{array}$ & 1232 kN.m & 1061 kN.m & 913 kN.m & 845 kN.m \\
\hline Ratio & 1.0 & 0.82 & 0.74 & 0.69 \\
\hline
\end{tabular}

4 
$1 \quad$ Figures

a)

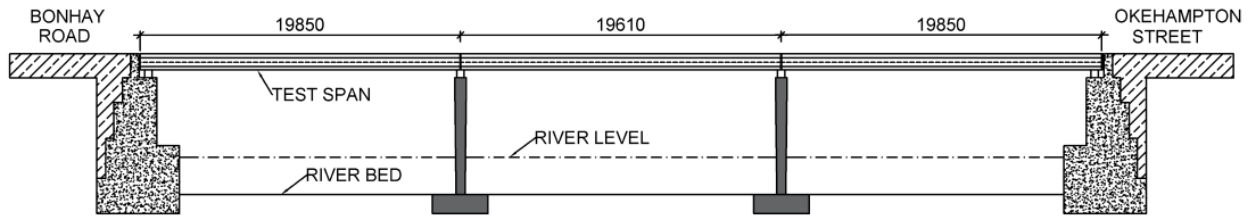

b)

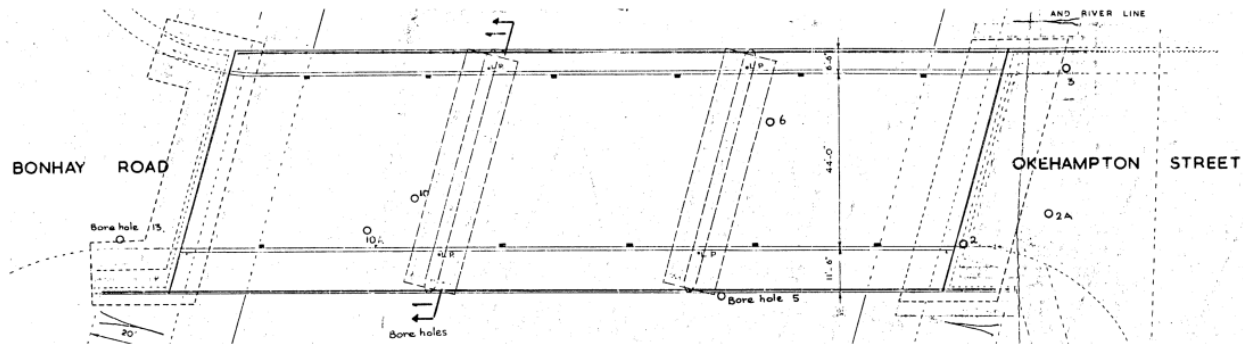

C)

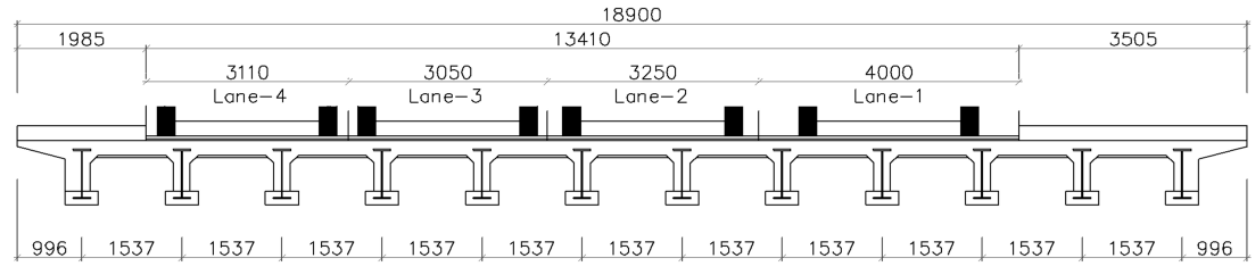

Fig. 1 (a) Bridge elevation (West). (b) Plan view of Exe North Bridge (c) Cross section of the superstructure

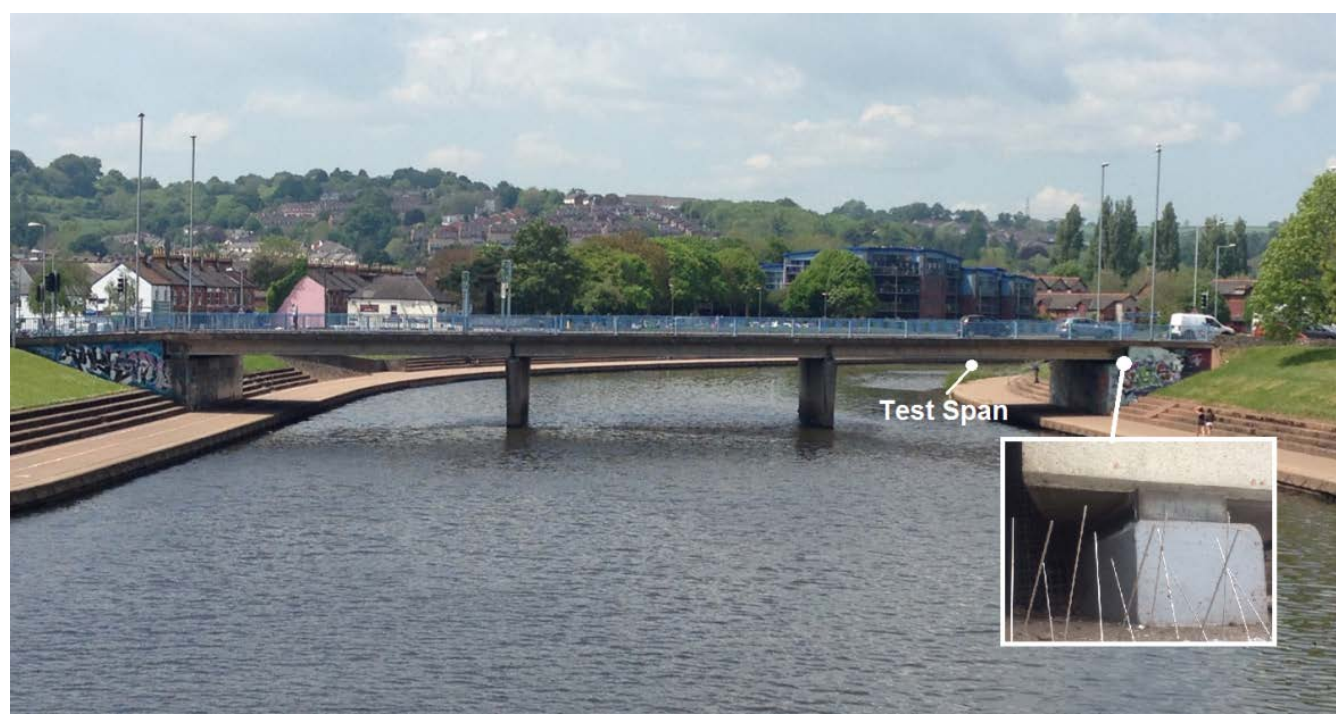

4 Fig. 2 Exe North Bridge spanning River Exe (East Elevation). The inset in the caption

5 is the photo of an elastomeric bearing at abutment location. 


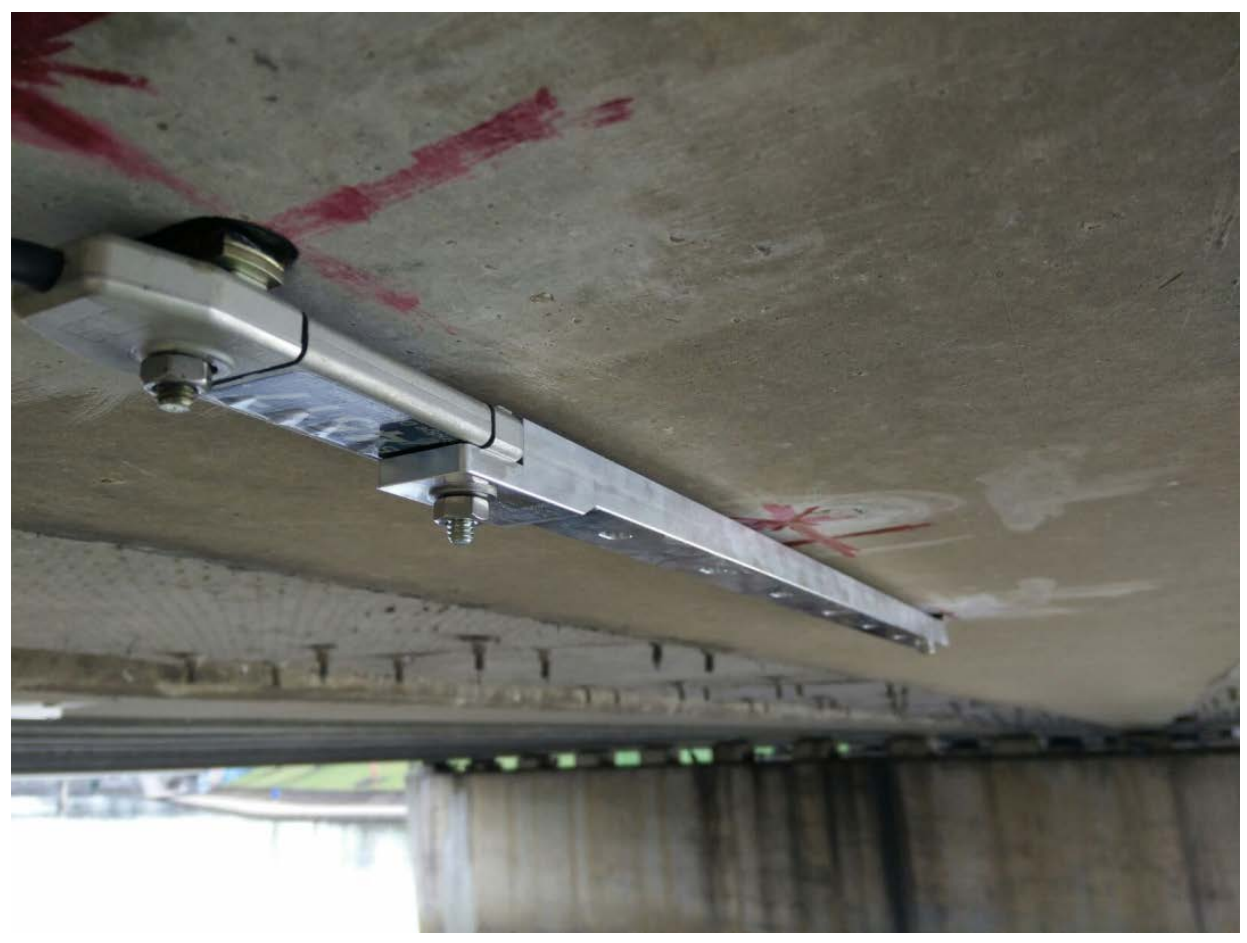

1 Fig. 3 Strain Transducer attached on a girder soffit with an aluminium extension rod

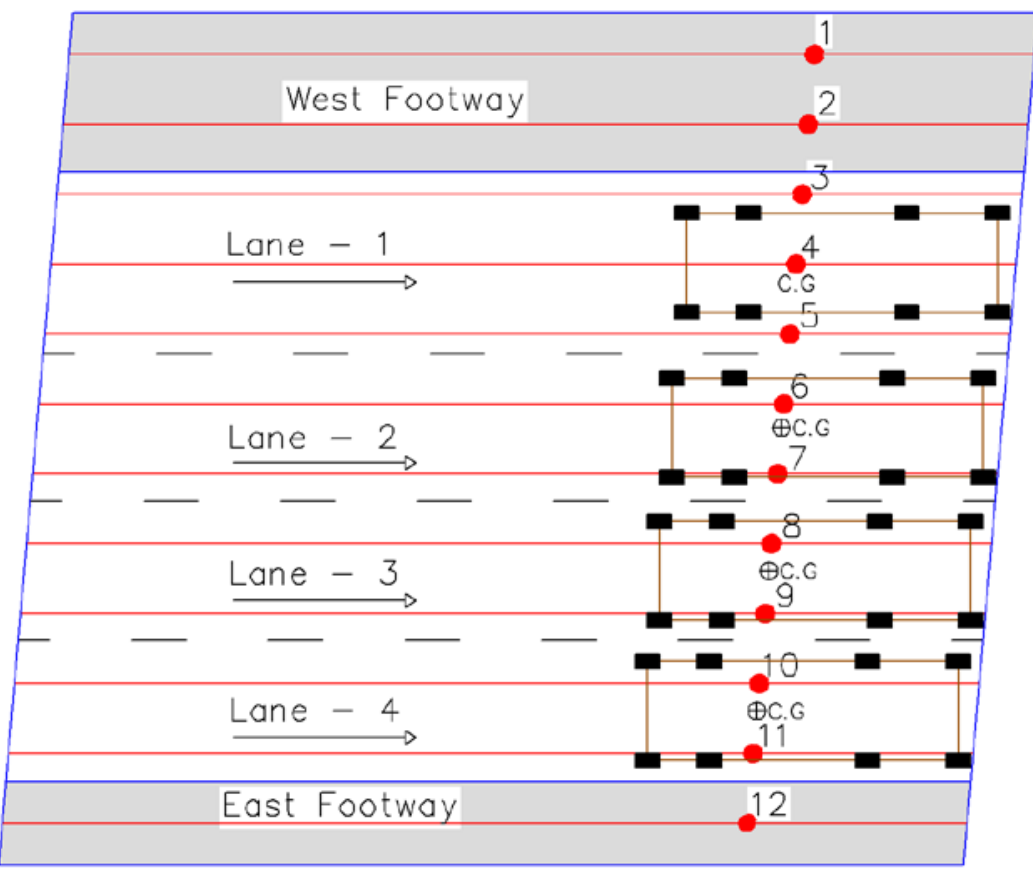

2 Fig. 4 Sensor and vehicle location layout 
a)

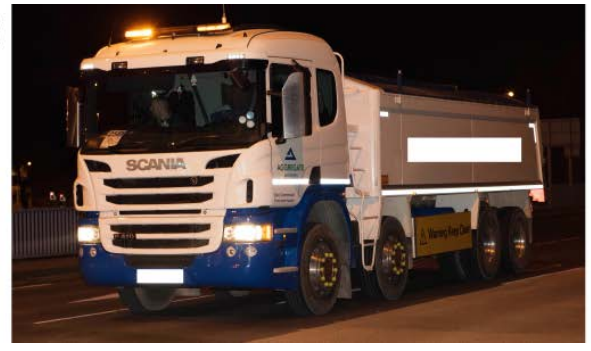

b)

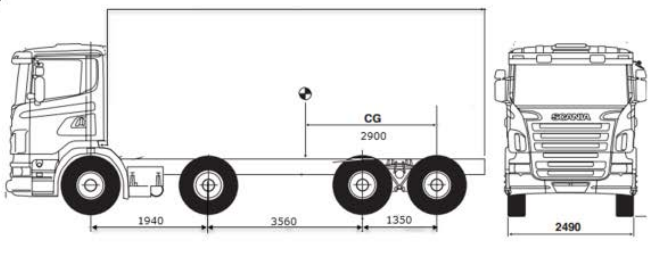

1 Fig. 5 (a) Test vehicle in the first lane during load testing (b) Axle configuration of the 2 test vehicle

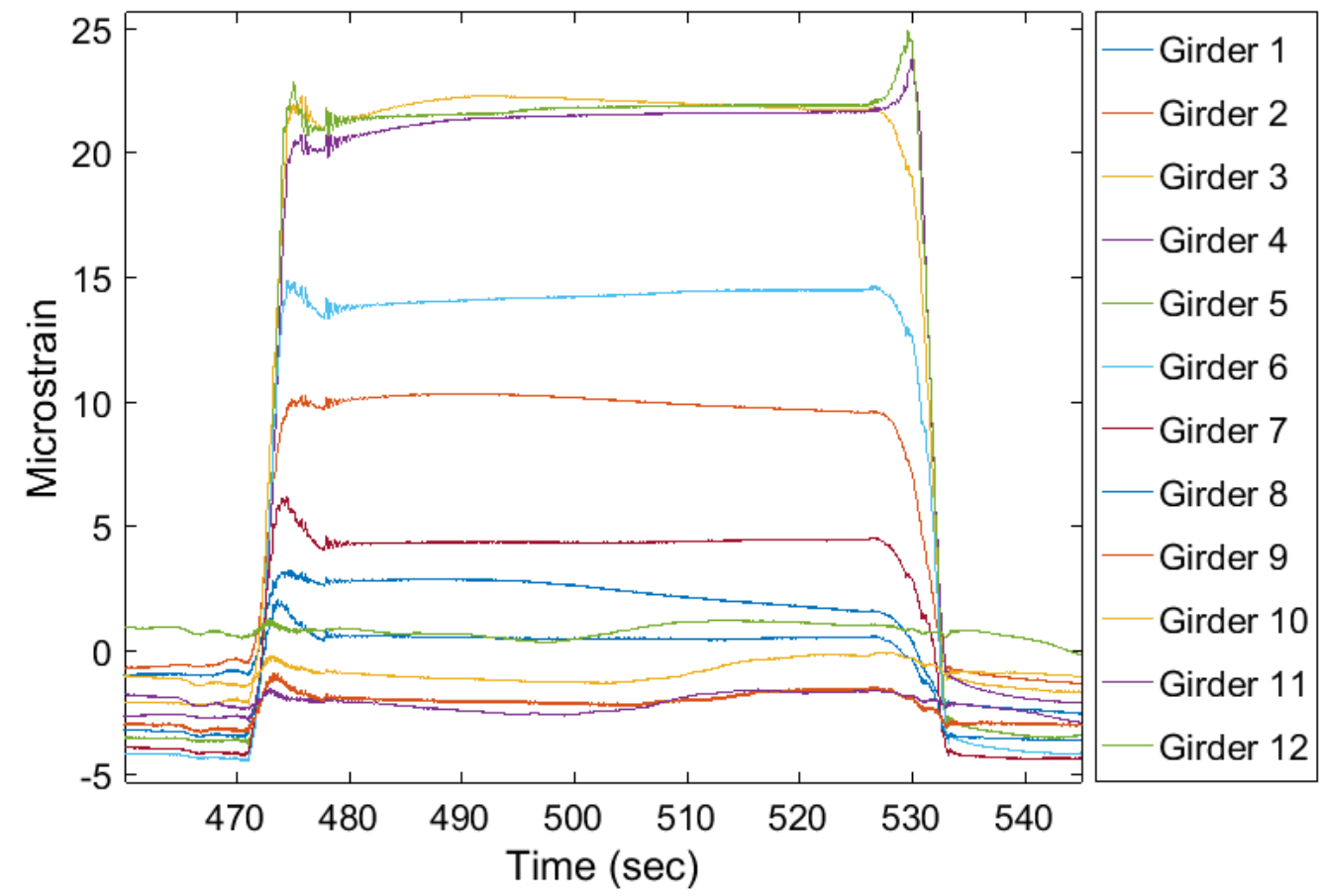

3 Fig. 6 Typical strain time history graph recorded during the test while vehicle 4 remaining stationary at Lane -1 


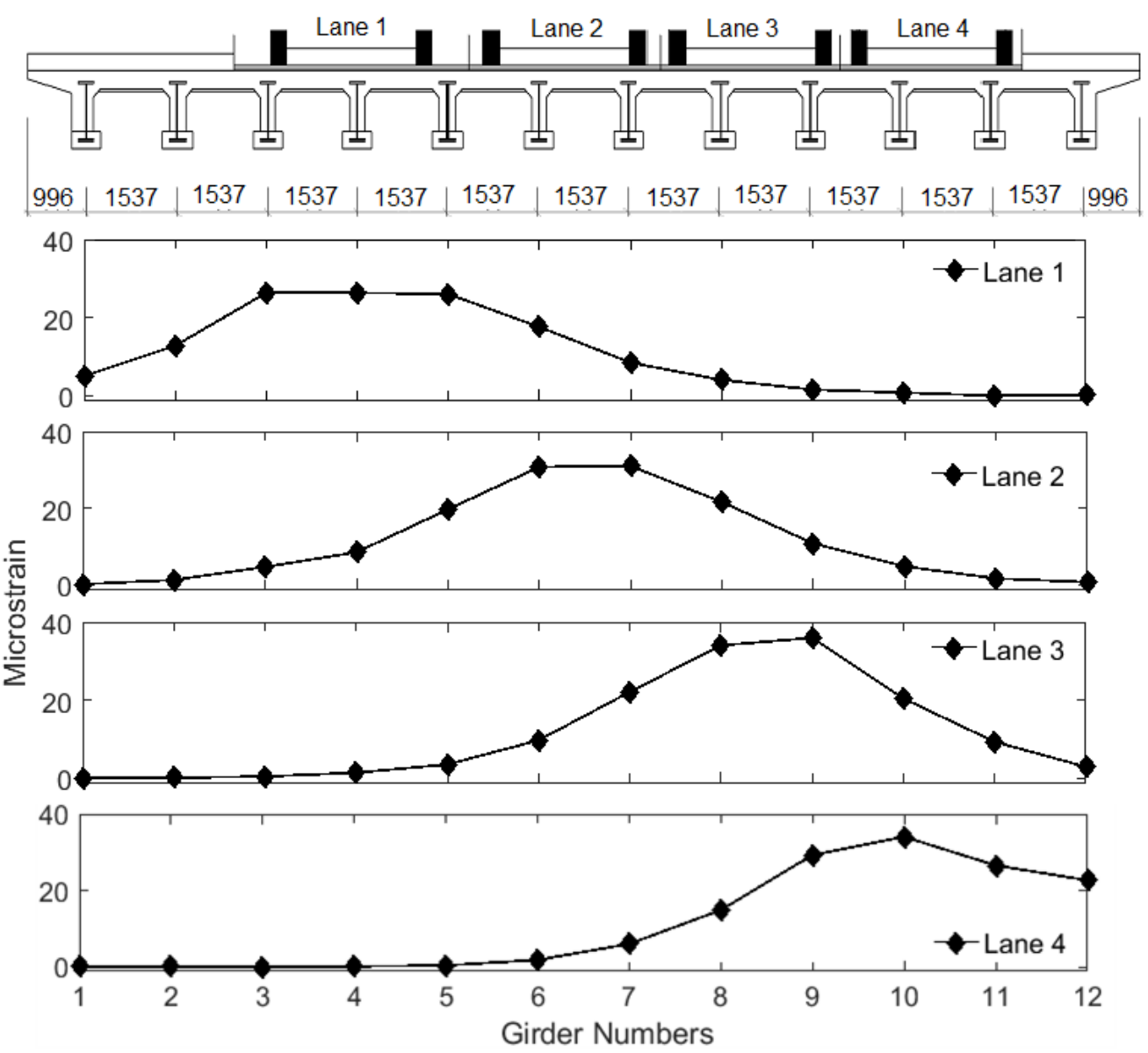

$1 \quad$ Fig. 7 Strains obtained at the girder soffits during the field test for each lane loading 2

a)

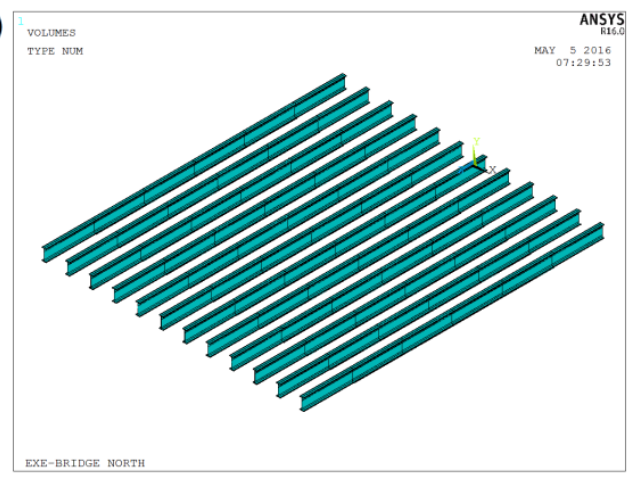

b)

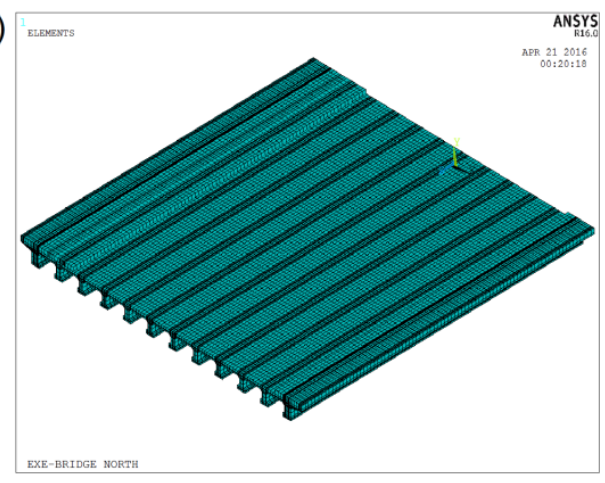

3 Fig. 8 (a) FE model of steel stringers (b) 3-D FE model of the bridge 
a)

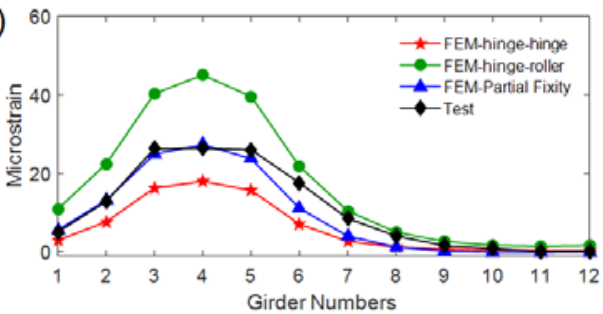

c)

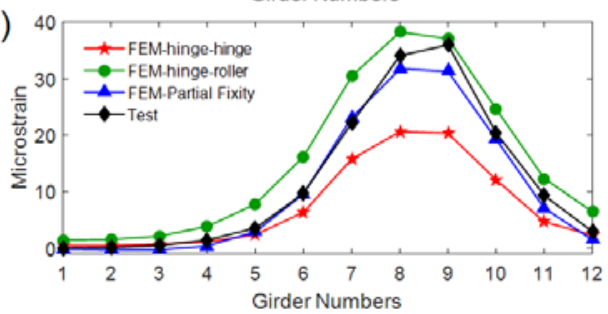

b)

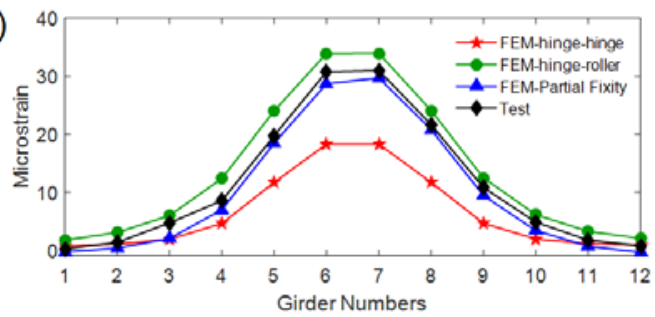

d)

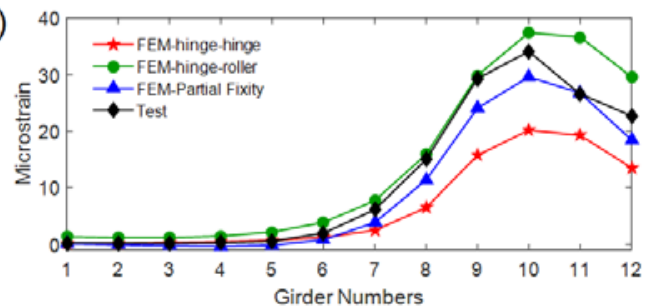

$1 \quad$ Fig. 9 Strains obtained at the girder soffits during field test and from FE model

2 (a) Lane 1 (b) Lane 2 (c) Lane 3 (d) Lane 4

a)

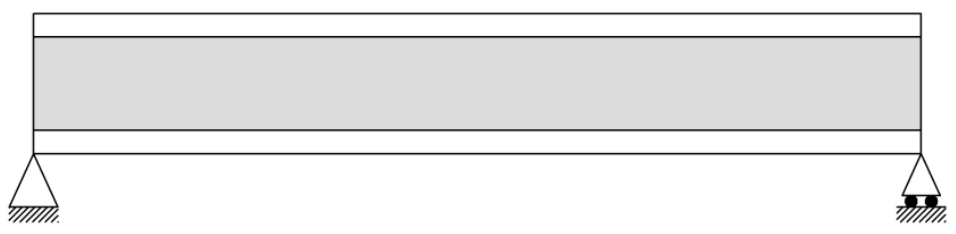

b)

c)

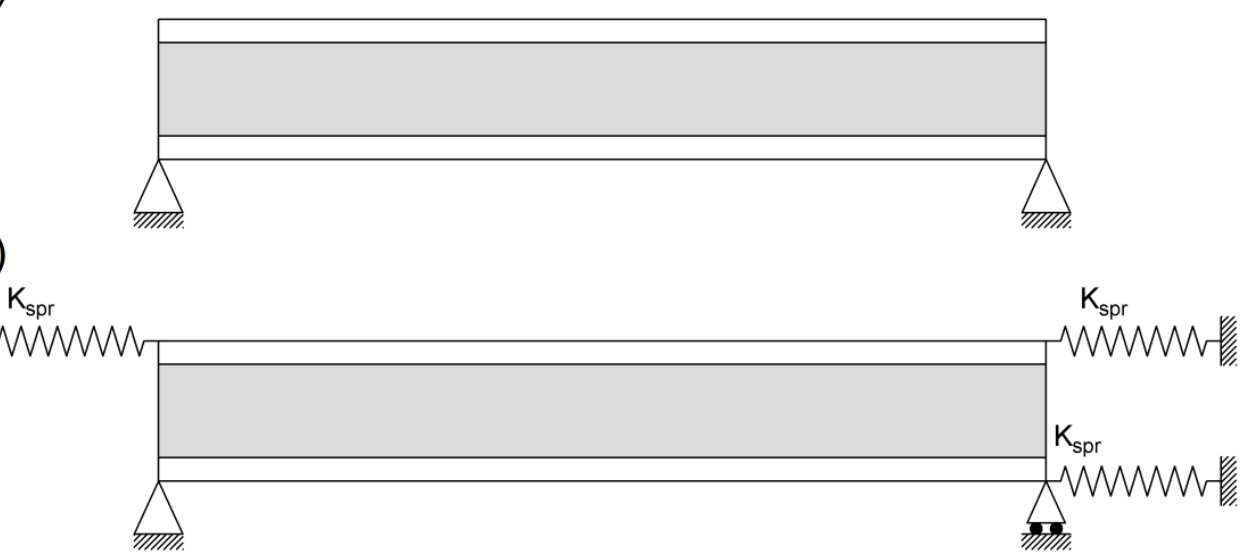

Fig. 10 Three cases of boundary conditions used for finite element analysis. a) hinge roller b) hinge - hinge c) partially fixed. 
a)

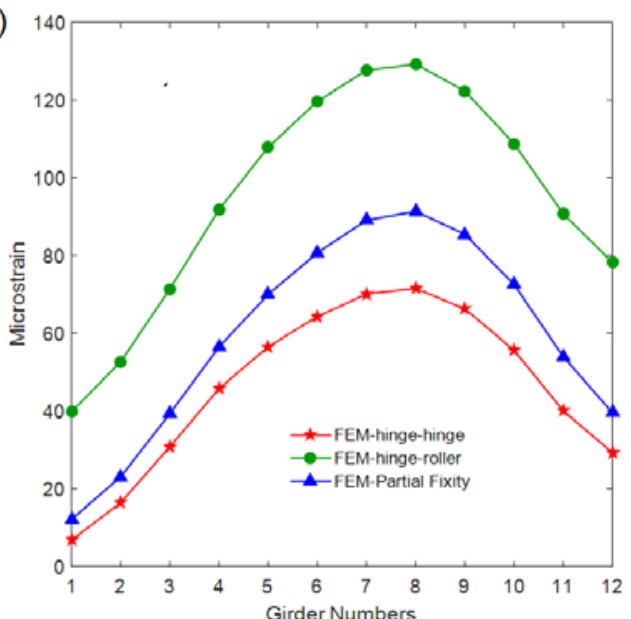

b)

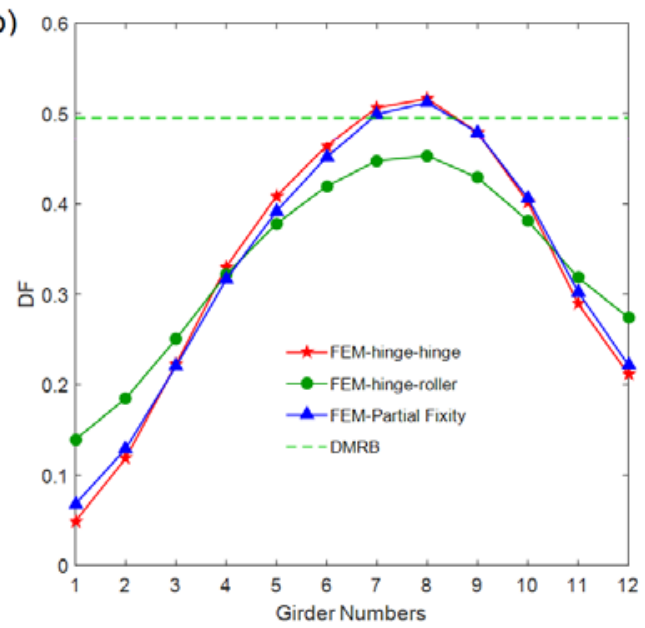

1 Fig. 11 (a) Strains at midspan under full lane loading (b) DFs at midspan 


\section{References}

2 [1] C. Caprani, "Traffic Microsimulation for Bridge Loading Assessment and Management", IABSE Symposium Report, vol. 99, no. 9, pp. 1486-1493, 2013.

4 [2] P. Das, Safety of bridges. London: Telford, 1997.

[3] B. Bakht and L. Jaeger, "Bridge Testing-A Surprise Every Time", Journal of Structural Engineering, vol. 116, no. 5, pp. 1370-1383, 1990.

[4] J. McConnell, M. Chajes and K. Michaud, "Field Testing of a Decommissioned Skewed Steel I-Girder Bridge: Analysis of System Effects", Journal of Structural Engineering, vol. 141, no. 1, p. D4014010, 2015.

[5] A. Puurula, O. Enochsson, G. Sas, T. Blanksvärd, U. Ohlsson, L. Bernspång, B. Täljsten, A. Carolin, B. Paulsson and L. Elfgren, "Assessment of the Strengthening of an RC Railway Bridge with CFRP Utilizing a Full-Scale Failure Test and Finite-Element Analysis", Journal of Structural Engineering, vol. 141, no. 1, p. D4014008, 2015.

[6] Ansys. Ansys, Inc., 2015.

[7] P. Barr, M. Eberhard and J. Stanton, "Live-Load Distribution Factors in Prestressed Concrete Girder Bridges", J. Bridge Eng., vol. 6, no. 5, pp. 298-306, 2001.

[8] A. Bishara, M. Liu and N. El-Ali, "Wheel Load Distribution on Simply Supported Skew I-Beam Composite Bridges", Journal of Structural Engineering, vol. 119, no. 2, pp. 399-419, 1993.

[9] Design manual for roads and bridges. London: Stationery Office, 2000.

[10] "Transport and Road Research Laboratory lab. report 722, Dynamic wheel load measurements on motorway bridges", TRRL, 1976.

[11] G. M.H, "Transport and Road Research Laboratory supplementary report 770, Results from the Hull axle weight survey.", TRRL, 1983.

[12] G. M.H and S. B.A, "Transport and Road Research Report Laboratory supplementary report 787, Results from axle weight surveys at Lichfield and Barbam.", TRRL, 1983.

30 [13] P. Dawe, Research perspectives. London: Thomas Telford, 2003.

[14] I. Buckle, S. Nagarajaiah and K. Ferrell, "Stability of Elastomeric Isolation Bearings: Experimental Study", Journal of Structural Engineering, vol. 128, no. 1, pp. 3-11, 2002. 